\title{
Insights into Corporate Social Responsibility Practices in Supply Chains: A Multiple Case Study of SMEs in the UK
}

\author{
Francesco Ciliberti* \\ Department of Environmental Engineering and Sustainable Development (DIASS) \\ Polytechnic of Bari, via de Gasperi, 74123 Taranto, Italy \\ email: cilibert@poliba.it
}

Denise Baden

School of Management University of Southampton

Building 2, Highfield Campus, Southampton, UK, SO17 1BJ

email: dab@soton.ac.uk

Ian A. Harwood

School of Management University of Southampton

Building 2, Highfield Campus, Southampton, UK, SO17 1BJ

email: iah@soton.ac.uk

\begin{abstract}
The aim of this paper is to investigate the pressure exerted by supply chain partners, especially large-scale business customers and public authorities, on small- and medium-sized enterprises (SMEs) to adopt corporate social responsibility (CSR) practices. More specifically, we analyze how SME suppliers perceive and respond to supply chain pressure and then we investigate if such pressure is effective. The analysis is carried out through four case studies within SMEs in the UK. These cases are deliberately chosen to illustrate to students and CSR practitioners the potential range of different viewpoints in relation to CSR and supply chain management.

The article suggests that, in order to enhance the perception of supply chain pressure as a CSR driver by SMEs, derived benefits should be more clearly identified (including moral, rational, as well as economic). There is also the risk that, when CSR requirements are imposed by large-scale business customers and public authorities, SMEs have difficulties in implementing CSR and consequently are tempted to behave opportunistically. An opportunistic behaviour can be associated to the large-scale business customers and the public authorities as well, when their commitment in CSR is perceived as only superficial. Thus there seems to be the need for a higher level of trust in such actors in order to share the potential benefits and costs related to CSR among all supply chain partners. In some cases, supply chain pressure can be detrimental to the existing initiatives voluntarily carried out by SMEs, which can consequently decrease their intrinsic motivation to engage.
\end{abstract}

Keywords: Corporate Social Responsibility, SME, supply chain, case studies

\footnotetext{
Corresponding Author

This case was prepared solely to provide material for classroom discussion. The author does not intend to illustrate either effective or ineffective handling of a managerial situation. The author has disguised some names and other identifying information to protect confidentiality. The views presented here are those of the case authors and do not necessarily reflect the views of Operations and Supply Chain Management: An International Journal. Copyright $@($ 2009 by Operations and Supply Chain Management: An International Journal and the authors. If you are an instructor and wish to adopt the case for your class, please contact the corresponding author or the special issue editor to obtain the teaching notes.
} 


\section{Introduction}

Whilst the actual components of corporate social responsibility (CSR) are essentially (and hotly) contested, there appears to have been a recent 'tipping point' (Gladwell, 2000) whereby the concept of CSR has now become embedded within a critical mass of organisations. CSR can be defined as "the voluntary integration, by companies, of social and environmental concerns in their commercial operations and in their relationships with interested parties" (Commission of the European Communities, 2001, p. 7). Based on this definition, the expression 'social responsibility' is used in this paper to refer to the social, environmental and economic attitudes and practices adopted by firms.

Investigating how small and medium-sized enterprises (SMEs), i.e. those having fewer than 250 employees and a turnover of up to 50 million Euros (Commission of the European Communities, 2003), deal with CSR along their supply chains is relevant for a number of reasons. Firstly, SMEs account for 99\% of all European Union (EU) enterprises and contribute up to $80 \%$ of employment in sectors such as textiles, construction, or furniture (Spence, 2007). Secondly, the concept of CSR "was developed mainly by and for large multinational enterprises" (Commission of the European Communities, 2002, p. 11), making a change in focus on to a smaller scale a welcome addition. As stressed by Lepoutre \& Heene (2006), CSR practices in large companies are significantly different from those developed in SMEs, due to the peculiarities of such firms. For example, most SMEs are directly managed by owners, are more linked to business partners and to the local community, and potentially lack resources and support to implement CSR. Thirdly, several benefits can be achieved by a company that behaves in a socially responsible way, among them: the improvement of financial performance and the reduction of operating costs; the enhancement of the corporate image and reputation; and the increase of customer loyalty and sales (Blowfield \& Murray, 2008). Such benefits go beyond the boundaries of a single firm and involve wider communities. To be effective in terms of CSR, companies thus need all supply chain partners to act in a socially responsible manner (e.g. Enderle, 2004).

Although CSR has a long history, applications of CSR and sustainability concepts to supply chains have only recently emerged (e.g. Roberts, 2003; Maloni \& Brown, 2006). Sustainable supply chain management (SCM) is defined as the management of supply chains where the three dimensions of sustainability - economic, environmental, and social - are taken into account (Seuring et al., 2006). Supply chain relationships are absolutely critical in a global marketplace to gain advantage from lower labour costs, since companies increasingly outsource business activities to developing countries (Wolters, 2003). When sustainable SCM principles are adopted, companies hold themselves accountable for the social and environmental impacts arising along their supply chains. Stakeholders, mainly consumers and non-governmental organizations (NGOs), are increasing pressure upon companies, especially large organizations, to engage in sustainable SCM practices (Green et al., 1996). Increasing numbers of large companies are in turn including environmental and social criteria in their procurement processes, which has a positive influence on the CSR behaviour of suppliers (Roberts et al., 2006). By encouraging their suppliers to adhere to fixed requirements, such organizations can also play a role in educating their supply chain partners in CSR-related activities (European MultiStakeholder Forum on CSR, 2004).

The aim of this paper is to investigate the pressure exerted by supply chain partners, especially largescale business customers and public authorities, on SMEs, i.e. when such partners specify CSR criteria either as a precondition for tendering to supply or as a variable to be considered in the purchasing decision alongside value-for-money (Baden et al., in press). Specifically, we analyze how SME suppliers perceive supply chain pressure and respond to it. We also investigate if such pressure is effective. The analysis is carried out by means of four case studies within SMEs in the UK, which typify different perspectives and reactions to supply chain pressure.

\section{Literature review}

SMEs often represent a critical part of the supply chain. Sustainable SCM offers opportunities to influence the operating practices of SMEs to incorporate environmental and social initiatives (e.g. Seuring et al., 2008). Together with the environment, employees, and the community, supply chain partners (i.e. customers and suppliers) represent key stakeholders for SMEs (Jenkins, 2006). 
Several authors (e.g. Jenkins, 2004 and 2006; Walker et al., 2008) discuss the CSR drivers in SMEs. As emerging from a literature review conducted by Ciliberti et al. (2008), the most cited CSR driver in SMEs is supply chain pressure. Most of the previous studies found that supply chain pressure on SMEs is high, especially when pushed by large-scale business customers (in particular, food retailers and manufacturers of furniture, automobiles, and electronic devices). For example, Roberts et al. (2006), in a survey on UK SMEs, found that exclusion from supply chains was the most often cited risk associated to an inadequate progress on CSR issues. According to these scholars, SMEs can feel that the environmental and social criteria included by large organizations in their procurement processes exclude them from competing for such contracts.

Large companies usually have to take responsibility also for their smaller suppliers' actions as they are more visible than such suppliers (Bowen, 2000). It is also easier for non-organisational stakeholder groups to pressure large companies to address social and environmental concerns, rather than pursuing a large number of their smaller suppliers (Hall, 2001). Since large-scale customers often dominate the supply chain, they can dictate conditions to smaller suppliers (e.g. Holmlund \& Kock, 1996), e.g. by seeking assurance that the SME is compliant with some defined CSR standards (Hamann et al., 2005) like the large-scale customer's code of ethics, Social Accountability 8000 (SA8000), and/or ISO14001. Large companies often require SME suppliers to provide evidence of the actions undertaken to improve the environmental and/or social performance (e.g. DTI, 2002; Jenkins, 2004). In some cases (e.g. Yu \& Bell, 2007), the SMEs citing supply chain pressure as one of the main drivers of their environmental or social improvements were found to be those with a higher level of internationalisation, which are directly affected by the global market.

On the other hand, irresponsible behaviour by large-scale customers can impede SMEs' efforts to engage in CSR practices (Bhide \& Stevenson, 1990). According to the European Multi-Stakeholder Forum on CSR (2004), "heavy demands placed on SMEs at the end of long supply chains can translate into pressure to cut costs in such a way that social and/or environmental responsibilities are jeopardised" (pp. 65-66). Another drawback from the SME perspective is that acquiring the necessary CSR credentials presents relatively higher costs for smaller firms due to fewer resources such as time, money, and expertise (e.g. Côté et al., 2008).

Many SMEs are somewhat cynical of being asked to demonstrate their CSR credentials by their customers, and view these requirements as an extra administrative burden. According to such firms, business customers only implement CSR in a formal way and are not really committed. Supply chain pressure can thus be perceived as a 'box-ticking exercise' (Baden et al., in press). This happens especially when buyer requirements are noncontractual and not subject to verification (Jørgensen \& Knudsen, 2006). Some SMEs also think that business customers should improve their CSR practices before asking them to demonstrate theirs. The perception is that buyers ultimately still make their purchasing decisions based more on price and delivery times (Jørgensen \& Knudsen, 2006).

In a survey on English SMEs, Baden et al. (in press) found that a third of the analyzed firms thought that imposed requirements would set lower standards then they would set for themselves, providing an indication of the 'ceiling effect', whereby once the imposed standards were reached, no further effort was taken. Supply chain pressure in such cases risks being counter-productive as it reduces the intrinsic motivation to engage in CSR beyond the set level.

The results of another survey on UK SMEs (Jenkins, 2006) suggest that internal drive rather than external pressure was their main motivation for CSR. Some external pressure was applied down the supply chain from customers and legislation, but this was weak and focused mainly on environmental rather than social credentials. Research on Chinese SMEs showed similar findings (Yu \& Bell, 2007). Most Chinese SMEs in the study did not consider an environmental record along the supply chain as an issue and argued that final customers had not pushed environmental pressures when choosing them as a firm to trade with. The situation was even worse in a social context, since Yu \& Bell (2007) found a very low market demand for social engagement. Worthington et al. (2006) conducted a multiple case study on South Asian-owned and/or managed SMEs in the UK and found almost no evidence of pressures in the supply chain nor from other stakeholder groups driving socially responsible behaviour in the sample organizations. Since Roberts et al. (2006) 
found that supply chain pressure was a weak force in persuading companies to undertake CSR, according to such scholars the success of supply chain pressure as a CSR driver may depend on how much SMEs trust the motivations of large organisations (Jenkins, 2006).

\section{Research design and methodology}

The aim of this paper is to investigate the CSRrelated pressures exerted by supply chain partners, especially customers (both public, i.e. central government or local authorities, or private, i.e. large businesses), on SMEs. We do not investigate the pressure applied by final customers (e.g. through consumers' associations or the involvement of mass media) since the previous literature review showed that they, as yet, do not exercise significant pressure directly on SMEs. We also do not investigate the pressure exerted by smaller businesses, since the literature review also showed that they do not have generally enough power to stimulate their suppliers to implement CSR practices.

Specifically, we address the following research questions:

1. How do upstream SME suppliers perceive supply chain pressure? For example, they may think that such pressure is a competitive advantage or alternatively a burden.

2. How do upstream SME suppliers respond to such pressure? For example, they may respond positively or negatively.

3. Is such pressure effective in order to increase CSR commitment in SME suppliers? For example, it can increase or decrease their motivation to implement CSR.

Denscombe (2003) highlights how a case study approach can unearth the subtleties and intricacies of complex social situations. Harrison \& Leitch (2000) also suggest that case studies are now an established approach for management research. Therefore, we have adopted a multiple case study design (Yin, 2003) incorporating four SMEs that had implemented CSR practices. Cases were selected on the basis of a replication logic (Yin, 2003), aiming for as much diversity as possible among the case firms in terms of their position with respect to the three research questions. We thus selected firms that have different perceptions about supply chain pressure, reply in different ways to such pressure, and experience different levels of effectiveness of such pressure. In selecting cases we also took into account different sizes and industries, in order to give as much generalizability as possible to our results. We chose SMEs from the UK, since in that country the role played by government in supporting CSR is evident. As an historical example, the former Prime Minister Blair created the position of Minister for CSR within the Department of Trade and Industry, a focal point for CSR within government by encouraging research and development on CSR issues. The richness of such different cases provides both literal and theoretical replication (Yin, 2003).

In total, four semi-structured interviews were conducted with owner/managers of these SMEs. All respondents were the main person in charge of strategy, generally being the founder or one of the directors. The interviews and observations were transcribed and summarized, and the results were fed back to the respondents for validation and verification. Then these reports were coded according to the literature review summarized in the previous section. To address inter-coder reliability, each of the authors read the transcriptions separately so as to develop an independent point of view, and then a comparison among the authors was conducted. When evaluations by the authors were conflicting, a discussion among the discordant authors was conducted until a final agreement was reached.

\section{Analysis}

Table 1 summarizes the information gathered from the analyzed firms. Their businesses came from a variety of sectors: manufacturing (e.g. printers), and the service sector (e.g. recruitment and cleaning). All of the analyzed firms supply largescale business customers or public authorities (located both in UK and in other EU countries). For each firm, information was given on its size, the products or services sold, the stakeholder groups towards which the firm is most responsible, the main motivation for CSR, if they experience pressure from large-scale customers or public authorities or both, the perception by SMEs on such pressure, the 
Table 1. Summary of the case organizations.

\begin{tabular}{|c|c|c|c|c|c|c|c|c|}
\hline Firm & Size & $\begin{array}{l}\text { Product/ } \\
\text { Services }\end{array}$ & $\begin{array}{l}\text { Stakeholder } \\
\text { groups towards } \\
\text { which } \\
\text { the firm is most } \\
\text { responsible }\end{array}$ & $\begin{array}{c}\text { Main } \\
\text { motivation } \\
\text { for CSR }\end{array}$ & $\begin{array}{l}\text { Pressure from large- } \\
\text { scale customers/ } \\
\text { public authorities } \\
\text { to engage } \\
\text { in CSR }\end{array}$ & $\begin{array}{l}\text { SMEsí } \\
\text { perception } \\
\text { of CSR }\end{array}$ & $\begin{array}{l}\text { SMEsí } \\
\text { response to } \\
\text { pressure } \\
\text { from } \\
\text { customers }\end{array}$ & $\begin{array}{l}\text { Effectiveness } \\
\text { of customer } \\
\text { pressure } \\
\text { to engage } \\
\text { in CSR }\end{array}$ \\
\hline UK1 & Small & Recruitment & Employees & External & Yes & $\begin{array}{l}\text { Both positive } \\
\text { and negative }\end{array}$ & Positive & Low \\
\hline UK2 & Medium & $\begin{array}{l}\text { Cleaning } \\
\text { services }\end{array}$ & Customers & External & Yes & Negative & Negative & Low \\
\hline UK3 & Small & Animal feed & Natural environment & Intrinsic & No & Slightly positive & Slightly negative & High \\
\hline UK4 & Medium & Printers & $\begin{array}{l}\text { EmployeesLocal } \\
\text { Local community } \\
\text { Customers }\end{array}$ & External & During tender processes & Slightly positive & Positive & Quite Low \\
\hline
\end{tabular}

response to this pressure, and its effectiveness. Among the case study firms, both small and medium firms are present. Three of the firms experienced pressure from their customers. In general, customers are very relevant for all the considered companies, whose missions mention these stakeholders.

The following sections expand on the summaries in Table 2 to provide more in-depth accounts of the four case SMEs and their views on CSR. Numerous verbatim quotations from respondents are embedded throughout the analysis in order to illustrate key points and increase validity.

\subsection{UK1}

UK1 is an environmental recruitment consultancy established in 1993. Clients are mostly located in Europe, Middle East, Australasia, and Asia. The company has a written environmental policy and also publishes a CSR report. UK1 believes that the most valuable asset for any business is the people employed. The corporate vision, namely "putting our people and our customers at the heart of our business", is to ensure that the company invests in the best therefore guaranteeing that the staff are well trained, informed, and qualified.

One of the company's objectives is to manage emissions by developing a carbon reduction plan with SMART (Specific, Measurable, Achievable, Relevant, Time-constrained) targets, whilst also raising the awareness of staff about climate change and empowering them to take action. The company was one of the first 100 participants of the Climate Neutral Network, i.e. an initiative led by the United Nations Environment Programme (UNEP) to assist companies achieving big cuts in greenhouse gas emissions.

In order to reduce emissions, the company invited Envirowise (i.e. a programme launched by the UK government in 1994 to help businesses increase profitability and reduce environmental impact) to conduct a thorough Environmental Audit. This included an examination of energy consumption and recommendations on how to reduce it. Waste to landfill, energy usage, water usage, and transport were areas identified as having significant environmental impact. The company is in the process of implementing some of Envirowise's recommendations, for example: (1) establishing a wormery to reduce waste to landfill by an estimated $50 \%$; (2) installation of thermostatic controls to the heating system to save energy; and (3) when possible, sourcing from local and environmentally assured suppliers. In 2007 and 2008, the company also offset employees' car travel emissions (to and from work and client visits) with Climate Care (a UK-based carbon offset company). The company feels that it is extremely important to give back to the community both locally and globally. By offsetting its carbon emissions, the company can help invest in innovative low carbon technology projects worldwide, thus helping to improve the quality of life for the communities involved. In 2008 the company also raised money for a wide spectrum of charities.

UK1 has to find the right candidates for its customers, which always try to drive the costs down ("we are seen as an unnecessary expense"). Large-scale business customers of UK1 work with preferred supplier lists, which include potential suppliers on the basis of social, health and safety, and 
environmental issues. The company had not been asked about social issues until two years ago, now these issues are becoming increasingly relevant. UK1 has to complete straightforward pre-tender questionnaires that ask if the firm has a health and safety and an environmental policy.

UK1 perceives supply chain pressure both as a potential competitive advantage and as a burden. As a potential competitive advantage, supply chain pressure is considered as a support to the formalization of CSR. Seven years ago, the company had to fill in for the first time a questionnaire on environmental issues for the Environment Agency: "at that time it was quite uncomfortable but it was actually very useful because it forced us to look at how we were answering those questions". Supply chain pressure thus helped UK1 to devise and implement an environmental policy: "Most of the people in the company are very aware of environmental issues. We were doing things well before, but we did not actually have an environmental policy until we were asked that question. Now we have got one."

As a burden, it is something extra that a company has to do ("another box that you have to tick"). According to the company, "the burden was us having to put a policy together and do the formal work". In addition, the firm believes that most of the customers that push pressure on them to implement CSR are not really committed: "The reality is that I do not think it makes a lot of difference to their decision-making what answers we give". However, the company has no difficulties in filling in pre-tender questionnaires, which are not very bureaucratic.

According to UK1, supply chain pressure can increase the motivation to implement CSR, but it might decrease the effectiveness of what a firm is doing: "Your effort goes into what you are being asked to do rather than what you think is the most appropriate and the most useful thing to do." Such pressure can also kill spontaneity and creativity to do positive things beyond the legal remit. According to the firm, "the main criticism is that it can stifle some creativity, if you have just got to tick boxes. Anyway such pressure did not stop us doing anything that we would have done otherwise". In the end, supply chain pressure is considered effective: "the overall improvement in the environmental performance of companies is definitely worth a slight frustration from our side".

One of the key points is making sure that the issues that are being addressed are the ones that are relevant to the company: "the time that it gets most frustrating for people and that has been for us as well is when you are being asked a series of questions that have no relevance to the businesses you are in".

\subsection{UK2}

UK2 is a cleaning and support services provider. The corporate mission is "to provide the highest standard of services to our clients at competitive prices using safe working methods, highly trained staff, and eco-friendly products and systems". The company's aim is to exceed customer's expectations as the quality leader in providing office, window, carpet, and floor cleaning and other related support services for commercial, industrial, professional, and retail facilities. UK2 defines itself as customer-focused and customerdriven. The company thinks that "deeds are more eloquent than words". Consequently they usually make a commercial offer: they visit the customer's facility, learn about the customer's needs, and give them their professional opinion free and at no obligation. The company has always considered environmental issues as extremely important and consequently has an environmental policy. Continuous initiatives are taken to reduce any negative effect caused by the company's operations to the environment. The directors are charged with the responsibility of ensuring that only those suppliers that satisfy the strictest code of conduct on environmental issues are used. According to the company's environmental policy, only equipment and materials that are environmentally friendly are used and in the event that a supplier is discovered in violation of such policy they will be removed from the approved list of suppliers. However, in the company's point of view: "We will use products that are as environmentally friendly as possible to get the job done, but that does not mean all of them are a hundred percent environmentally friendly."

UK2 has to complete questionnaires submitted by its customers on health and safety, especially focused on the Control of Substances Hazardous to Health. According to the internal policy on health and safety, the company has a continuous program for the systematic development of standards and procedures concerned with the prevention of accidents and damages to health. The application of these standards and procedures is recognized as an integral part of effective resource management and supervision at all levels. 
Supply chain pressure is not perceived as a competitive advantage: "Anybody can fulfil environmental or health and safety criteria. It is very easy to tick the boxes." Such pressure is instead perceived as a "waste of time". According to UK2, "most of it is rubbish". As an example, in the opinion of the firm, although central government pushes pressure on companies, the government itself "does not understand what they are talking about". An example is recycling: "they insist on recycling. Well, sometimes it costs more. So we remove the products to where they are going to be recycled, but they do not understand. How are we going to recycle the plastic bottles? It is never thought through really". In the opinion of the firm, "most of it is sound bites from politicians. Most of the stuff is driven by people who do not understand what they are doing".

UK2 is aware of the chance of an opportunistic approach by SMEs in replying to supply chain pressure. As an example: "As of somebody selling the product, you find out what the client wants and then you fit your product round it." UK2 is not motivated to be green due to the government pressure: "people do it. We do it because the world now demands it". In its opinion, what all the small companies can save by being green is still little compared to what the government wastes. According to the firm, most of the small companies adopt environmental practices by the very nature of what they do, for example because using less bottles and concentrates of detergents is also cost-effective and easier to control: "We do CSR because it is a natural part of the business, not because we are driven to do it. If you are not ethical you will not stay in business for long".

\subsection{UK3}

UK3 was established in the 1920s and has remained in the control of one family ever since. The company stocks a wide range of leading products (e.g. feeds, bedding, medications, and supplements) to keep horses, pets or livestock in the best health. The staff are trained and offer advice on animal nutrition and health. The company also supplies electric fencing and equestrian hardware.

UK3 have to respond to large buying groups such as dairy farmers who apply pressure for service and price. UK3 is not asked about health and safety, environmental or social issues by customers. According to the UK3 respondent: "We do not consciously get involved in ethical projects, but as a small organisation we tend to operate ethically and responsibly within our own small sphere. We do not have to think about things on a global basis like a multinational might have to. We will not sit down at a board meeting and decide what our ethical policy should be, but we work to ethical standards because that is the sort of people we are. On the environmental side, we own a mile or so of river and with people like the Environment Agency we work hard to look after and maintain that. There is no commercial advantage to do so, but it is part of our ground and that is what we should look after, that kind of thing."

UK3 would have no problems in dealing with such pressure as long as it is a 'level-playing field', with equal pressure being placed on all firms in the marketplace. "In the agricultural world, very often we do not see a level-playing field. Someone might say we need to do certain things over here, and that is the standard, but then they buy it from abroad where the standards are worse but it is cheaper. So we satisfy ourselves, but we vote with our pockets. The farming of pigs is a very good example of that. We bring in a standard here which gives everyone a nice warm glow, but at the end of the day we buy pig products from abroad where it is cheaper because they do not have those standards."

Supply chain pressure could be negative because, according to the firm, SMEs do not want more regulation, which would cause an increase in the administrative burden they have to deal with: "There are enough hoops to jump through as it is." There could also be the chance of opportunistic behaviour by SMEs, but according to UK3 it is unlikely that such firms would risk being detected by customers as being dishonest. "For example, Waitrose (a UK large-scale food retailer) demands higher social or environmental standards. So if they ask for food made from non-genetically modified (GM) crops then the farmers will have to certify that they come from non-GM crops (...) It might be a bit like box-ticking, but I doubt they would risk being dishonest."

According to UK3, if the supermarkets included social or environmental criteria into buying decisions, SMEs in the agricultural sector would be encouraged to be more responsible. According to the firm, in order for supply chain pressure to be more effective, final customers have to accept to pay a price premium for CSR: "We accept products from farmers that are certified as non-GM, and it is certified. But then there is a price premium and it is up to the customer if they will pay that." 


\subsection{UK4}

The company's mission is "to provide the best service and product, within our field, of any printing company in Britain". Customers include the leading UK publishers of technical, financial and educational work, scientific and professional associations, societies, institutions, and universities. The company was established in 1884 and now continues as a private business in its fifth generation of management and direction by the same family. UK4 is now a specialist print firm with nearly 200 employees, housed in a large modern purpose built factory, and utilising the latest and most efficient plant and technology available. The company has obtained accreditation in the ISO14001 and Occupational Health and Safety Assessment Series (OHSAS) 18001 standards, and Forest Stewardship Council (FSC).

UK4 feels a responsibility to work in the local community. Consequently they try to support local initiatives, e.g. in colleges, and by means of such practices they try to "give something back to a community which is clearly giving us a resource, which is the people, to do our job well." The company is under an increasing financial pressure from its customers. According to UK4, showing their social or environmental or health and safety credentials "is a major requirement now for any large tender, so a lot of our work will be tendered through the European Union processes (...) And frankly if we do not have all the ticks in the boxes we would not even pass the stage of prequalification questions. So environmental policies tick, Investors in People tick, quality standards tick, Forest Stewardship Council, tick tick tick. If we do not have those, not a chance."

Supply chain pressure to engage in CSR is perceived as "a burden that has to be addressed sometimes begrudgingly, but it can also be an advantage if we perceive the pressure is in a direction that can bring value to our supply chain and is, therefore, worth investing appropriate resource in".

The company decided to obtain the FSC certification "because of slight but growing pressure from within the industry and particularly from high level prospects, e.g. government tenders. We took the view that what we were doing was right and the investment followed; subsequently, as it happens, this has proved to be wise, given that a lot of our work must now be produced on FSC materials, which means we would be excluded from this work had we not taken the initiative some years ago".
The firm also asks its own suppliers to fulfil the requirements of the forest management standard and the tracing of forest-derived products. To check their compliance with FSC, the firm tends to inspect suppliers instead of submitting long questionnaires to them: "We do not tend to create forty-page questionnaires about it. What we tend to do is what we inspect. We would not necessarily expect them to have all sorts of certificates, but we will inspect what they do and where they do it".

According to UK4, there is a strong risk of opportunistic behaviour (i.e. "a box-ticking exercise") when dealing with such pressure: "we talk quite openly to our competitors, there is a federation that would monitor us, which is fascinating because we actually talk about what is going on in the market. When dealing with European tenders, most of our competitors said: 'oh we just tick the boxes, no one ever checks'. We are therefore at a disadvantage because we are not lying about it".

Such pressure is considered an incentive because "companies dare not, not do it". However it can also be a disadvantage, especially for smaller firms, because related efforts and costs can be very high: "The smaller you are, the percentage of effort and cost involved to achieve some of the social or environmental standards can be quite alarming. We have probably half a dozen international standards, and they all need to be monitored and maintained and so on. You practically need full time staff to do it. Well if you have twenty or thirty people you cannot afford it, because the standards are practically the same. So for us the overhead is relevant, for the smaller businesses some shorter cuts may be taken". The company did not reduce its commitment due to a lower level set by a standard: "if we have set it at a higher level, it is because we believe the benefits to the bottom line are for us, therefore if that ultimate benefit means we have gone past some qualification marker, so would be just one step ahead when they raise the bar, if they ever do next time".

One problem concerns the existence of several standards: "we actually do not think FSC is likely to be the international standard for long, and it is already being overtaken possibly by others". Customers are now "listening to other standards being bandied around as maybe the international one, the standard of the future. And obviously all these standards will gradually change over time".

According to UK4, "we try to justify everything on the bottom line but there are still (other) things in life. When we built our latest factory, we built it 
environmentally, well beyond the standards of the time, because what the standards were at the time were not acceptable to us. So what we did was we built ways to avoid doing that and to recycle it. It is now becoming law and that is great. It was something we did that was not for the bottom line. It was extremely expensive and it was the right thing to do". In the end, UK4 believes that "our decisions are made from well judged arguments which are sometimes brought about by external pressures and just as often from internal pressure".

\section{Discussion}

The case study firms have different perceptions of supply chain pressure as a CSR driver and respond in various ways to it. The effectiveness of such pressure on SMEs implementing CSR is a questionable issue.

\subsection{How SMEs perceive supply chain pressure}

Werther \& Chandler (2006) suggest that engagement in CSR activity can be driven by the moral case (business-society relationship is interdependent, see UK2 and UK3), the rational case (be proactive to gain social legitimacy and avoid sanctions, see UK4) and/ or the economic case (UK1).

The analyzed companies perceive supply chain pressure both as a competitive advantage and as a burden. Supply chain pressure to undertake CSR may provide a competitive advantage if related benefits are higher than the attendant costs. The incurred costs may depend on several parameters, e.g. if the social or environmental impact of the SME is not strong (UK1), and if the requirements defined by the customers are not too challenging (UK4). Perceived costs can depend upon whether the firm takes a short or a long-term view. For example, UK4 took on board short-term costs to improve environmental standards that turned out to be of benefit to them in the long-term. Benefits are in most cases commercial: CSR can be a necessary requisite for SMEs being suppliers of large companies or public authorities (especially when joining EU tenders), since obtaining a social or environmental standard can cut off potential non-certified competitors (UK4). In addition, implementing environmental practices can potentially be costeffective (UK2). In some cases benefits could be more difficult to measure, i.e. when supply chain pressure helped companies formalizing their CSR strategy and practices (UK1), although these benefits could be as relevant as or even more significant than the commercial advantages. Supply chain pressure can also be perceived as a burden because it forces companies to do some formal work in addition to the routine work (UK1). This additional work is in some cases perceived as bringing no value to the company (UK2).

\subsection{How SMEs respond to supply chain pressure}

Supply chain pressure can push or even force firms to have a written policy to deal with CSR, e.g. an environmental policy (UK1, UK2), a health and safety policy (UK2) and a CSR report (UK1), or to obtain a social or environmental standard like ISO14001 (UK4) or FSC (UK4) or a health and safety standard like OHSAS18001 (UK4).

There is the risk that, by imposing CSR requirements to their suppliers, large companies transfer to them the attendant costs and thus make it more difficult in particular for the smaller companies to implement CSR practices. As a consequence, SMEs can be tempted to behave opportunistically (UK2, UK3, and UK4), i.e. to declare they fulfil CSR requirements even if this is actually not true. In order to reduce the risk of an opportunistic behaviour, a level-playing field would be in some cases (UK3) preferred. The frequency and thoroughness of the audits conducted by customers can also decrease the risk of opportunism (UK3).

Opportunistic behaviour can also be associated with large business customers (UK1), which may claim to incorporate social or environmental criteria in their purchasing decisions while in practice selecting suppliers based only on price. Similarly, central government and local authorities can be perceived as not genuinely operating for the public good (UK2) if their CSR requirements demonstrate insufficient understanding of the procedures that the companies have to implement in order to fulfil the requirements. Thus there seems to be the need of a higher trust in such actors and a better communication with them in order to share among all supply chain partners all the potential benefits and costs related to CSR. This partly extends the existing literature (Jenkins 2004, Jørgensen and 
Knudsen 2006), which focused only on trust in large business customers and not in public authorities.

Some of the analyzed companies are very pragmatic when dealing with CSR (UK2, UK3), especially when procuring products from their suppliers. This is mostly due to cost considerations. In general, SMEs wish to minimise regulation (UK3), which is associated to an increase in the administrative burden. There also seems to be the potential for further improvements in the behaviour of SMEs as a partner of upstream suppliers along their supply chain. As a consequence of the adoption of social or environmental standards, it is possible for SMEs to transfer in turn pressure to their own suppliers (UK4). In the case of UK4, a direct inspection is preferred to check the compliance of suppliers, rather than using self-evaluation questionnaires, because it is considered to be more effective.

\subsection{The effectiveness of supply chain pressure}

The effect on a supplier's motivation is a controversial point. On the one hand, according to some of the case firms (UK3), supply chain pressure is effective in increasing such motivation. On the other hand, according to other case firms (UK1), supply chain pressure can be detrimental to the initiatives they voluntarily carried out and consequently can decrease their motivation to engage in CSR. This result seems to confirm the 'ceiling effect' described by Baden et al (in press). When SMEs are already implementing CSR (UK1), it is more difficult for them to adapt to requirements defined by large business customers or public authorities. In this case, they have to modify their CSR strategy to fulfil such requirements. Consequently there is the risk that the spontaneity of the companies is stifled and thus such firms can decrease their effectiveness in dealing with CSR as a result of reluctant compliance. It is thus a key point that the requirements defined by customers are relevant also for the supplier companies.

Interestingly, the 'level-playing field' induced by supply chain pressure can be perceived both as negative (UK1) and positive (UK3). In the latter case, the company does not implement a higher number of CSR practices than its competitors and thus does not have a competitive disadvantage. This happens when SMEs do not trust how customers evaluate their
CSR commitment and when SMEs give a low value to CSR. If SMEs want to be proactive, the negative effects of the 'level-playing field' can also be softened (as in the case of UK4). In this case, SMEs do not decrease their commitment because they believe their CSR practices will be the new level-playing field in the future.

UK4 raised the issue of the multitude of different standards which impose a significant cost on smaller businesses who do not have the resources to monitor all the various criteria and requirements. The fact that standards change over time increases the cost burden further. UK 3 claimed that potential improvements could also be focused on the relationships with final customers. When such customers become more aware of CSR and are willing to pay a price premium for products sold by socially responsible companies, benefits deriving from CSR could increase and be shared among all the supply chain actors.

\section{Conclusions and insights for further research}

In general, we can conclude that supply chain pressure can be effective in order to stimulate CSR in small and medium companies. However, this pressure is not the only CSR driver in these companies. SMEs are also pushed to implement CSR by their ethical values. Both internal and external drivers can push the same company (as in the case of UK4) to CSR. In order to enhance the perception of SMEs about supply chain pressure as well as the effectiveness of such pressure, several means can be used:

(1) When benefits (moral, rational or economic) deriving from CSR are not clearly identifiable, SMEs should be supported by their large-scale business customers or public authorities. In addition, such support can also help clarifying how benefits can be distributed among the supply chain actors.

(2) The risk of an opportunistic behaviour both on the SME suppliers' side and on their business customers' or public authorities' side could be reduced through a wider diffusion of social or environmental standards that rely on third independent parties, due to the periodical audits conducted by such parties on both sides. 
(3) Such standards could solve the problem experienced by SMEs when dealing with different requirements defined by different business customers or public authorities. By having, for example, a single standard (preferably an accreditation system) for a whole sector, SMEs would not have to demonstrate their social or environmental commitment each time large-scale business customers or public authorities request them to do so. They would only have to deal with the periodical audits conducted by the accreditation authority. By passing such audits, they would automatically achieve the requirements defined by supply chain partners. It is relevant, due to the scarce resources available to SMEs, that such a prospective standard is as lean as possible (the forthcoming ISO26000 standard may be a step in the right direction).

(4) In order to increase the awareness of consumers and consequently make them willing to pay price premiums for CSR, SMEs could consider investing in communication activities aimed at educating final customers. Since the smaller companies have limited resources and visibility, it is more likely that communication activities will be conducted by medium-sized firms that act as chain directors, which could have the adequate structure to define such a marketing strategy.

The support from large-scale business customers or public authorities should be necessary when dealing with all the above-mentioned issues, since SMEs generally do not have adequate resources to do so themselves. If such customers are able to view the pressure on smaller suppliers as a way to improve the performance of suppliers and consequently of the entire supply chain and not only as a means to transfer them costs, it is likely that supply chain pressure could become an even more significant driver in the future, as seen recently when Wal-Mart held a sustainability summit amongst its suppliers in China (http://www.wal-martchina.com/ english/news/2008/20081006.htm). Yu \& Bell (2007) also reveal that Chinese SMEs presented a better environmental or social performance when under supply chain pressure to do so. For example, in most cases SMEs having certified management systems in place were responding to foreign clients' requirements. Therefore if supply chain management was more widely adopted, supply chain pressure may become more effective in motivating SMEs towards sustainable practice.

Further research could investigate in more detail some of the issues that are most controversial in our analysis, i.e.: the risk of opportunistic behaviour by competitors and large-scale customers; the need of a higher trust in public policies; the risk of decreasing the effectiveness of firms if they have to fulfil many different CSR requirements. Additional case studies and a survey on SMEs, in cases located in other countries, could be useful to these ends.

\section{Discussion Questions}

1. Is it possible to align the issues that are addressed by the CSR requirements defined by customers with the issues that are relevant to their smaller suppliers? If yes, how?

2. Can the use of management systems like ISO14001, ISO26000, OHSAS18001 and FSC help SMEs in complying with the requirements defined by customers?

3. Is it possible to stimulate final customers to pay a price premium for CSR?

4. Can supply chain partners address the issues that are related to the existence of different standards (that also change over time)?

\section{References}

Baden, D.A., Harwood, I.A. \& Woodward, D.G. (in press). The effect of buyer pressure on suppliers in SMEs to demonstrate CSR: An added incentive or counterproductive? European Management Journal, forthcoming.

Bhide, A. \& Stevenson, H.H. (1990). Why be honest if honesty doesn't pay. Harvard Business Review, 68(5), pp. 121-129.

Blowfield, M. \& Murray, A. (2008). Corporate Responsibility. A Critical Introduction. Oxford University Press, Oxford.

Bowen, F. (2000). Environmental visibility: A trigger for organisational response? Business Strategy and the Environment 9(2), pp. 92-107.

Ciliberti, F., Pontrandolfo, P. \& Scozzi, B. (2008). Small business social responsibility in the supply chain. Working paper. 
Commission of the European Communities (2001). Green Paper. Promoting a European Framework for Corporate Social Responsibility, COM (2001) 366 final, Brussels.

Commission of the European Communities (2002). Communication from the Commission Concerning Corporate Social Responsibility: A Business Contribution to Sustainable Development, COM (2002) 347 final, Brussels.

Commission of the European Communities (2003). Recommendation of 6th May 2003 concerning the definition of micro, small and medium-sized enterprises. Official Journal of the European Union, 2003/ 361/E.

Côté, R., Lopez, J., Marche, S., Perron, G.M. \& Wright, R. (2008). Influences, practices and opportunities for environmental supply chain management in Nova Scotia SMEs. Journal of Cleaner Production, 16(15), pp. 1561-1570.

Denscombe, M. (2003). The Good Research Guide: For SmallScale Social Research Projects. Buckingham, Open University Press.

DTI (2002). Engaging SMEs in Community and Social Issues. DTI, London.

Enderle, G. (2004). Global competition and corporate responsibilities of small and medium-sized enterprises. Business Ethics: A European Review, 13(1), pp. 51-63.

European Multi-Stakeholder Forum on CSR (2004). Final Results $\mathcal{E}$ Recommendations, Final Report.

Gladwell, M. (2000). The Tipping Point: How Little Things Can Make a Big Difference, Little, Brown and Company, New York.

Green, K., Morton, B. \& New, S. (1996). Purchasing and environmental management: Interactions, policies and opportunities. Business Strategy and the Environment, 5(1), pp. 188-197.

Hall, J. (2001). Environmental supply chain innovation. Greener Management International 35, pp. 105-119.

Hamann, R., Agbazue, T., Kapelus, P. \& Hein, A. (2005). Universalizing corporate social responsibility? South African challenges to the International Organization for Standardization's new social responsibility standard. Business Society Review, 110(1), pp. 1-19.

Harrison, R.T. \& Leitch, C.M. (2000). Learning and organization in the knowledge-based information economy: Initial findings from a participatory action research case study. British Journal of Management, 11(2), pp.103-119.

Holmlund, M. \& Kock, S. (1996). Buyer dominated relationships in a supply chain: A case study of four small-sized suppliers. International Small Business Journal, 15(1), pp. 26-40.

Jenkins, H. (2004). A critique of conventional CSR theory: An SME perspective. Journal of General Management, 29(4), pp. 37-57.
Jenkins, H. (2006). Small business champions for corporate social responsibility. Journal of Business Ethics, 67(3), pp. 241-256.

Jørgensen, A.L. \& Knudsen, J.S. (2006). Sustainable competitiveness in global value chains: How do small Danish firms behave? Corporate Governance: The International Journal of Effective Board Performance, 6(4), pp. 449-462.

Lepoutre, J. \& Heene, A. (2006). Investigating the impact of firm size on small business social responsibility: A critical review. Journal of Business Ethics, 67(3), pp. 257273.

Maloni, M.J. \& Brown, M.E. (2006). Corporate social responsibility in the supply chain: An application in the food industry. Journal of Business Ethics, 68(1), pp. 35-52.

Roberts, S. (2003). Supply chain specific? Understanding the patchy success of ethical sourcing initiatives. Journal of Business Ethics, 44(2), pp. 159-170.

Roberts, S., Lawson, R. \& Nicholls, J. (2006). Generating regional-scale improvements in SME corporate responsibility performance: Lessons from Responsibility Northwest. Journal of Business Ethics, 67(3), pp. 275-286.

Seuring, S., Muller, M. \& Morana, R. (2006). Case study research in the field of sustainable supply chain management. In Mendibil, K. \& Shamsuddin, A. (eds.). Moving Up the Value Chain Vol. 2. University of Strathclyde, Glasgow, pp. 747-756.

Seuring, S., Sarkis, J., Müller, M. \& Rao, P. (2008). Sustainability and supply chain management: An introduction to the special issue. Journal of Cleaner Production, 16(15), pp. 1545-1551.

Spence, L.J. (2007). CSR and small business in a European policy context: The five "C" $\mathrm{C}$ of CSR and small business research agenda 2007. Business Society Review, 112(4), pp. 533-552.

Walker, H., Di Sisto, L. \& McBain, D. (2008). Drivers and barriers to environmental supply chain management practices: Lessons from the public and private sectors. Journal of Purchasing and Supply Management, 14(1), pp. 69-85.

Wolters, T. (2003). Transforming international product chains into channels of sustainable production. The imperative of sustainable chain management. Greener Management International, 43, pp. 6-13.

Werther, W.B. \& Chandler, D. (2006). Strategic Corporate Social Responsibility: Stakeholders in a Global Environment. Sage, Thousand Oaks.

Worthington, I., Ram, M. \& Jones, T. (2006). Exploring corporate social responsibility in the U.K. Asian small business community. Journal of Business Ethics, 67(2), pp. 201-217. 
Yin, R.K. (2003). Case Study Research. Design and Methods. Sage, Newbury Park.
Yu, J. \& Bell, J.N.B. (2007). Building a sustainable business in China's small and medium-sized enterprises (SMEs). Journal of Environmental Assessment and Policy Management, 9(1), pp. 19-43.

Francesco Ciliberti is a Research Fellow in Sustainable Supply Chain Management at the Polytechnic of Bari, Italy, where he develops his research at the Department of Environmental Engineering and Sustainable Development. He has a PhD in Advanced Production Systems and is author of several papers published in international journals. His research is mainly focused on corporate social responsibility and supply chain management.

Denise Baden achieved her PhD at the University of Southampton in the School of Psychology and spent a number of years teaching and doing research in the area of social psychology, self and identity. She joined the School of Management in 2005 working in the area of entrepreneurial personality. Her current interests are sustainability, business ethics, CSR, work psychology and entrepreneurship.

Ian Harwood's industrial experience includes over a decade of managing organisational change programmes mainly within the pharmaceutical industry. His research interests cover a broad range of topics relating to Corporate Responsibility and Sustainability, with a more recent focus on ethical supply chains and procurement decision making. Other CR-related interests include the role of business in environmental issues (especially related to risk management). 